\title{
Optimization of Fermented Tofu with High Isoflavone Content through Variation of Inoculum Percentages and Ratios of Lactobacillus plantarum, Lactobacillus acidophilus, and Leuconostoc mesenteroides
}

\author{
Dea Indriani Astuti \& Zahra Noviana \\ Microbial Biotechnology Research Group, School of Life Sciences and Technology, \\ Institut Teknologi Bandung, Jalan Ganesha 10, Bandung 40132, Indonesia \\ Email: zahra.noviana@lipi.go.id
}

\begin{abstract}
Tofu is a traditional food that can be found in several countries, such as Indonesia and Japan. Tofu is often made using the backslopping method, which brings the risk of pathogenic microorganism contamination and can lead to failure in production. Standardization of the production process is necessary in order to yield highly nutritious tofu that is safe to be consumed. In this research, standardization was investigated by variation of the inoculum percentages and ratios of Lactobacillus plantarum (a), Lactobacillus acidophilus (b), and Leuconostoc mesenteroides (c). The inoculum percentages used in this research were $7.5 \%, 10 \%$, and $12.5 \%$, while the inoculum ratios between $\mathrm{a}, \mathrm{b}$, and c were (a:b:c) $2: 1: 1 ; 1: 2: 1 ; 1: 1: 2$; and $1: 1: 1$. The optimum inoculum ages for $a, b$, and $c$ were 8,6 , and 2 hours respectively. The highest growth rates of a, b, and c were $0.060 \mathrm{~h}^{-1}, 0.054 \mathrm{~h}^{-1}$, and $0.092 \mathrm{~h}^{-1}$ respectively. The highest lactic acid production rates of $\mathrm{a}, \mathrm{b}$, and $\mathrm{c}$ were $0.072 \% \mathrm{~h}^{-1}, 0.063 \% \mathrm{~h}^{-1}$, and $0.126 \% \mathrm{~h}^{-1}$ respectively. The inoculum percentage and ratio that produced the highest isoflavones content was $12.5 \%(2: 1: 1)$, with the highest bacterial population growth rate being $0.019 \mathrm{~h}^{-1}$, the highest formation rate of lactic acid being $0.045 \% \mathrm{~h}^{-1}$, and the isoflavone aglycones level being $0.445 \mathrm{mg} / \mathrm{mL}$.
\end{abstract}

Keywords: fermentation; isoflavone; lactic acid; lactic acid bacteria; tofu.

\section{$1 \quad$ Introduction}

Tofu is traditional food which has a high nutritional content. The texture, flavor, and aroma of tofu make it well appreciated by society. Some of the nutrients contained in tofu are carbohydrates, fat, protein, calcium, iron, and sodium [1]. The main ingredient of tofu is soymilk. The manufacturing process can be carried out with the addition of vinegar or with the back slopping method, which involves the addition of tofu whey.

Lactic acid bacteria produce lactic acid during fermentation from carbohydrate breakdown and they can perform proteolysis, which breaks down proteins into

Received September $24^{\text {th }}, 2013,1^{\text {st }}$ Revision November $4^{\text {th }}, 2013,2^{\text {nd }}$ Revision November $25^{\text {th }}, 2013$,

Accepted for publication November $26^{\text {th }}, 2013$.

Copyright () 2013 Published by ITB Journal Publisher, ISSN: 2337-5760, DOI: 10.5614/j.math.fund.sci.2013.45.3.5 
simpler compounds that are easier to digest, such as amino acids [2]. Lactic acid bacteria are widely used, especially in the food industry, because they fall under the category of Generally Recognized as Safe (GRAS), which indicates that food products processed using lactic acid bacteria are safe for consumption. They are also used to give texture, taste, aroma, and content of nutrients to fermented foods [3]. The use of lactic acid bacteria with suitable inoculum percentages and ratios can produce tofu with the desired texture, taste, aroma, and content of nutrients.

One of the advantages of using fermentation by lactic acid bacteria to produce tofu is the production of isoflavones by the lactic acid bacteria. Isoflavones have similarities with the estrogen hormone. Estrogen is produced primarily in the ovary and in the adrenal cortex in the kidneys. This hormone is needed for the normal growth and maintenance of the body in adults. In women, in addition to its function in the reproductive system, this hormone plays a role in the process of bone formation [4]. We hypothesized that fermentation using lactic acid bacteria could increase the isoflavone aglycones content in tofu.

Fermented soy products are a potential source of isoflavones and their consumption may contribute to reduction in the rates of coronary heart diseases, atherosclerosis, type 2 diabetes, and particular types of carcinogenesis [5]. Recent studies have shown that phytochemicals in soy are responsible for prevention of osteoporosis, a hereditary chronic nose blood syndrome, and autoimmune diseases [6]. Therefore it is more advisable to consume soybeans after having undergone fermentation [7]. Isoflavones can be found in soybeans in the form of glycosides, such as genistin and daidzin. Lactic acid bacteria produce the $\beta$-glucosidase enzyme, which is involved in the conversion of isoflavone glycosides into isoflavone aglycones [8]. Lactobacillus plantarum is known to be able to express this enzyme [9] and as the lactic acid bacteria that is most ideal for use in the isoflavones conversion process [10]. Lactobacillus acidophilus also produces the same enzyme [10], while Leuconostoc mesenteroides can produce the same enzyme when it is grown in media containing arbutin [11]. Isoflavone glycosides are hardly absorbed in the small intestine compared to isoflavone aglycones, because they have a larger molecular weight and more hydrophilic properties. Daidzin and genistin are also less active in comparison with daidzein and genistein (aglycone form of daidzin and genistin) [5].

This research aimed to produce tofu with a high isoflavone content through a fermentation process using lactic acid bacteria. The lactic acid bacteria used were: Lactobacillus plantarum, Lactobacillus acidophilus, and Leuconostoc mesenteroides. Optimization of the fermentation process was investigated by applying variations of inoculums percentage and ratios. The best inoculums 
variation was determined by the highest amount of isoflavone aglycones (daidzein and genistein) in the tofu produced through fermentation.

\section{$2 \quad$ Materials and Methods}

\subsection{Lactic Acid Bacteria}

The lactic acid bacteria (Lactobacillus plantarum, Lactobacillus acidophilus, and Leuconostoc mesenteroides) used in this research were obtained from the microbiology laboratory, School of Life Sciences and Technology, Institut Teknologi Bandung, and were identified by biochemical testing.

\subsection{Optimum Inoculum Age Determination}

Determination of the optimum inoculum age was done by generating growth curves. Lactobacillus plantarum, Lactobacillus acidophilus, and Leuconostoc mesenteroides were inoculated into MRSB media and then incubated at room temperature to activate the bacteria. After 24 hours, each of the bacteria cultures, with a density of $10^{6} \mathrm{CFU} / \mathrm{mL}$, was inoculated into a $27 \mathrm{~mL}$ soymilk medium and then incubated for 24 hours at $37^{\circ} \mathrm{C}$.

Samples were taken every two hours. A $0.1 \mathrm{~mL}$ sample was inoculated into an MRSA medium using the spread method to determine the bacterial amount [12]. The acidity levels $(\mathrm{pH})$ of the samples were measured with a $\mathrm{pH}$ meter, while determination of the lactic acid concentrations was done by acid-base titration. For titration, a $5 \mathrm{~mL}$ sample was mixed with $10 \mathrm{~mL}$ de-ion and 5 drops of phenolphthalein and then titrated using $0.1 \mathrm{M} \mathrm{NaOH}$. The growth curves were obtained by plotting time (x axis) against the log of cell numbers (y axis). The age of the inoculum was optimum when the bacteria were at their $\mu$ max, which was approximately at half of their log phase.

\subsection{Optimization of Fermentation Process}

Inoculum preparation was conducted by inoculating the soymilk medium with $10 \%(\mathrm{v} / \mathrm{v})$ of active bacteria with a density of $10^{6} \mathrm{CFU} / \mathrm{mL}$ and then incubating it in accordance with each optimum inoculum age at $37^{\circ} \mathrm{C}$. The inoculum percentages and ratios were then varied and inoculated into new soy milk media with a density of $10^{6} \mathrm{CFU} / \mathrm{mL}$. The inoculum percentages used in this research were $7.5 \%, 10 \%$, and $12.5 \%(\mathrm{v} / \mathrm{v})$, while the inoculum ratios were 1:1:1, 2:1:1, 1:2:1 and 1:1:2 (Lactobacillus plantarum : Lactobacillus acidophilus : Leuconostoc mesenteroides). The fermentation process was conducted in 8 hours. Every 2 hours a sample was taken to measure the total bacterial amount 
through total plate count, $\mathrm{pH}$ with a $\mathrm{pH}$ meter, and lactic acid concentration through acid-base titration.

\subsection{Isoflavones Extraction and Detection using HPLC}

Isoflavone aglycones measurement was conducted on all optimization variations. Tofu isoflavone aglycones measurement was done by taking a $3 \mathrm{~mL}$ sample and transferring it into a tube and then extracting it with $12 \mathrm{~mL}$ methanol. The sample was stirred for 24 hours at room temperature. The insoluble residue was separated by centrifugation with a speed of $8000 \mathrm{rpm}$ at $25^{\circ} \mathrm{C}$ for 10 minutes and then filtrated with Whatman No. 1 filter paper. The supernatant $(12 \mathrm{~mL})$ was evaporated using a rotary evaporator until $1 \mathrm{~mL}$ solution was obtained, which was then filtered with a $1 \mathrm{~mL}$ syringe filter $(0.2$ $\mu \mathrm{m})$ for analysis through high performance liquid column chromatography (HPLC). The motion phase used was A solution $\left(\mathrm{H}_{2} \mathrm{O}\right.$ : acetic acid $\left.=3: 97\right)$ and B solution (methanol : acetic acid $=97: 3$ ) with a flow velocity of $1 \mathrm{~mL} /$ minute. The sample $(10 \mu \mathrm{L})$ was injected into the column $(\mathrm{C} 18,30 \mathrm{~cm})$ and the isoflavones were separated through the system with an elution gradient system (0\% A : 100\% B for 5 minutes followed by $100 \%$ A : $0 \%$ B for 50 minutes and then $0 \% \mathrm{~A}: 100 \%$ B for 5 minutes). The isoflavones level was monitored using a UV-Vis detector with a wavelength of 260 [13].

\section{$3 \quad$ Results and Discussion}

\subsection{Optimum Inoculum Age of Lactobacillus plantarum, Lactobacillus acidophilus, and Leuconostocc mesenteroides}

The optimum inoculum ages of Lactobacillus plantarum, Lactobacillus acidophilus, and Leuconostoc mesenteroides were determined through growth curves (Figure 1). The optimum inoculum ages of Lactobacillus plantarum,

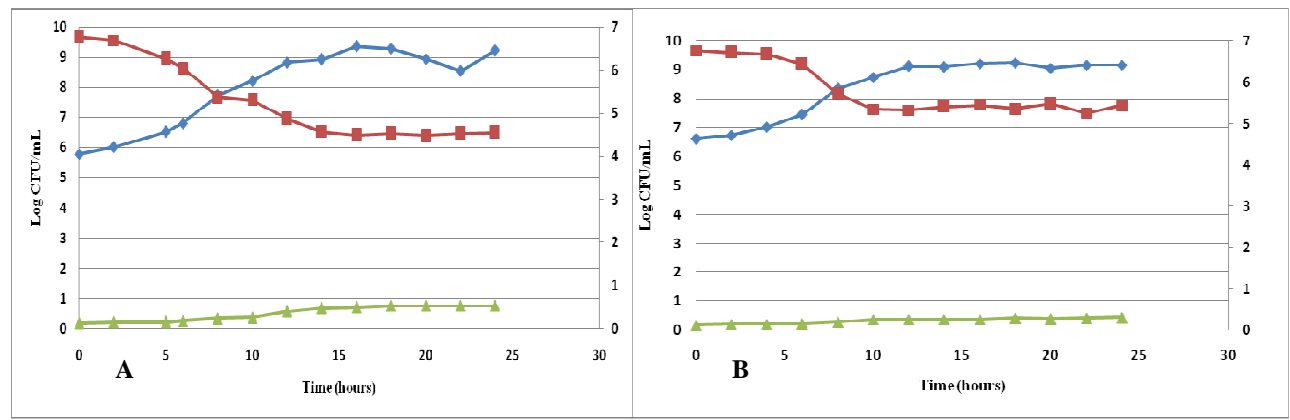

Figure 1 Growth curves of Lactobacillus plantarum (A), Lactobacillus acidophilus (B), and Leuconostoc mesenteroides (C) in soymilk medium; incubated for 24 hours; without agitation; at $37^{\circ} \mathrm{C}$. 


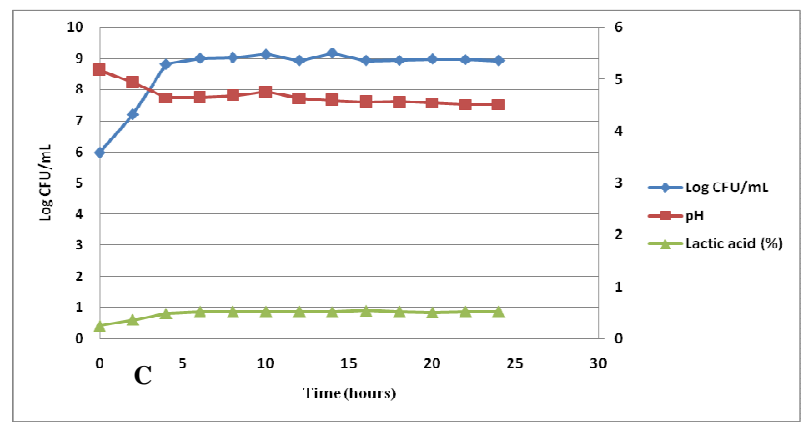

Figure 1 Continued. Growth curves of Lactobacillus plantarum (A), Lactobacillus acidophilus (B), and Leuconostoc mesenteroides (C) in soymilk medium; incubated for 24 hours; without agitation; at $37^{\circ} \mathrm{C}$.

Lactobacillus acidophilus, and Leuconostoc mesenteroides were 8 hours, 6 hours, and 2 hours respectively. The highest growth rates $(\mu)$ of $L$. plantarum, L. acidophilus, and L. mesenteroides in soymilk medium were $0.060 \mathrm{~h}^{-1}, 0.054$ $\mathrm{h}^{-1}$, and $0.092 \mathrm{~h}^{-1}$ respectively. The highest lactic acid production rates of $L$. plantarum, L. acidophilus, and L. mesenteroides in soymilk medium were $0.072 \% \mathrm{~h}^{-1}, 0.063 \% \mathrm{~h}^{-1}$, and $0.126 \% \mathrm{~h}^{-1}$ respectively.

\subsection{Optimization of Tofu Fermentation Using 7.5\% Inoculum}

During the optimization process using 7.5\% inoculum, the bacterial amount increased during fermentation. The highest bacterial population growth rate during optimization with $7.5 \%$ inoculum (Figure 2A) was $0.094 \mathrm{~h}^{-1}$. This value was obtained using Lactobacillus plantarum, Lactobacillus acidophilus, and Leuconostoc mesenteroides in a proportion of 2:1:1. The highest specific growth rates with the use of single cultures of Lactobacillus plantarum, Lactobacillus acidophilus, and Leuconostoc mesenteroides were $0.060 \mathrm{~h}^{-1}$, $0.054 \mathrm{~h}^{-1}$, and $0.092 \mathrm{~h}^{-1}$ respectively. The results show that the use of a mixed culture increased the bacterial population growth rate compared with the use of a single culture.

All variations of ratios using 7.5\% inoculum (Figure 2B) showed a pH decrease during fermentation, which lasted for 8 hours. The decrease in $\mathrm{pH}$ may have been caused by acid production by Lactobacillus plantarum, Lactobacillus acidophilus, and Leuconostoc mesenteroides. The decline in $\mathrm{pH}$ for each ratio showed no significant difference. The $\mathrm{pH}$ for each ratio did not differ significantly after 8 hours of fermentation, but after the first 6 hours of fermentation it could be seen that the $\mathrm{pH}$ decreased more quickly when using the mixed culture with a ratio of 1:1:1 (L. plantarum : L. acidophilus : $L$. 
mesenteroides) with a $\mathrm{pH}$ value of 4.97 . The lowest $\mathrm{pH}$ after 8 hours of fermentation was 4.83 , which was obtained using Lactobacillus plantarum, Lactobacillus acidophilus, and Leuconostoc mesenteroides in a ratio of 2:1:1. The highest production rate of lactic acid (Figure 2C) using 7.5\% inoculum was $0.045 \% \mathrm{~h}^{-1}$. This result was obtained using the mixed culture with a ratio of 1:1:1 (L. plantarum : L. acidophilus : L. mesenteroides).
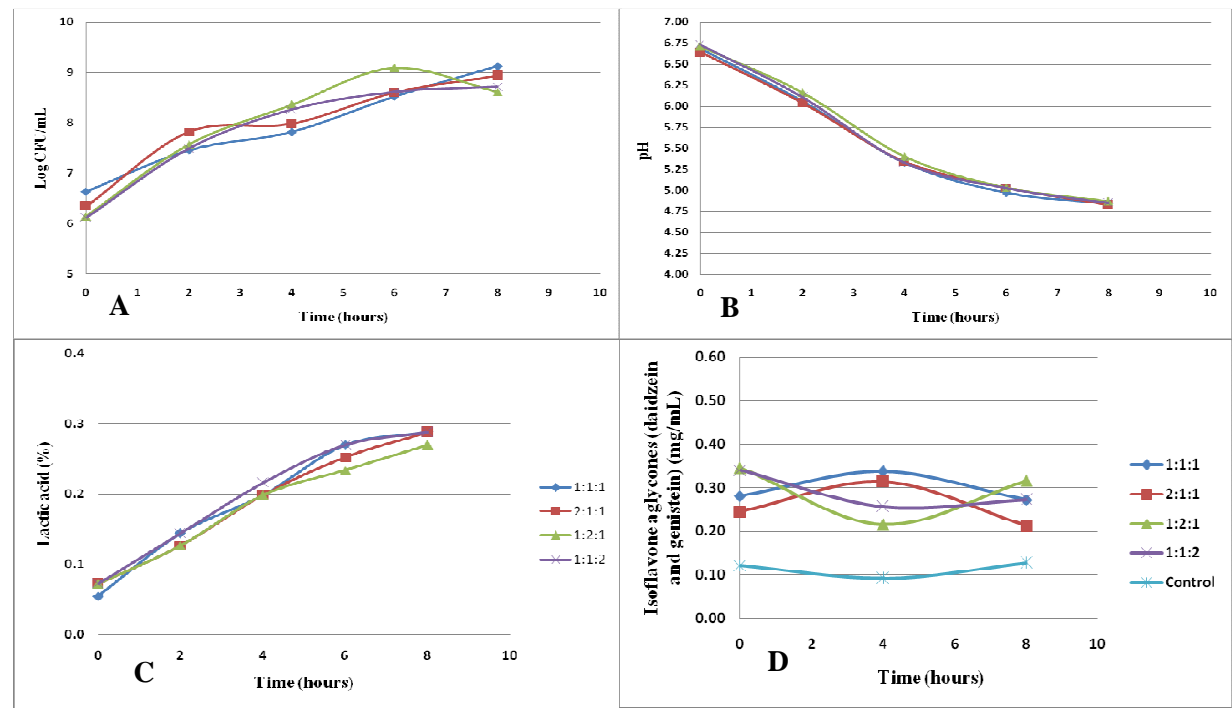

Figure 2 Optimization using 7.5\% inoculum; with the total amount of bacteria (A), $\mathrm{pH}$ (B), lactic acid (C), and isoflavone aglycones (daidzein + genistein) (D) changes during 8 hours of fermentation. The inoculum proportions between $L$. plantarum, L. acidophilus, and L. mesenteroides were 1:1:1, 2:1:1, 1:2:1, and $1: 1: 2$

The highest concentration of isoflavone aglycones (daidzein and genistein) with the $7.5 \%$ inoculum (Figure 2D) was obtained through the mixed culture with a ratio of 1:2:1 (L. plantarum : L. acidophilus : L. mesenteroides), with a value of $0.316 \mathrm{mg} / \mathrm{mL}$. This ratio first showed a decrease in the amount of isoflavone aglycones, after which it increased significantly from the $4^{\text {th }}$ to the $8^{\text {th }}$ hour. The increase in isoflavone aglycones concentration may have been caused by the formation of daidzein and genistein by the $\beta$-glucosidase enzyme produced by the lactic acid bacteria [8], while the decrease in isoflavone aglycones concentration may have been caused by a cell mechanism that converts genistein into other compounds, so it doesn't disturb cell division [14]. The high concentration of isoflavones aglycones after eight hours of fermentation may have been caused by the high enzymatic activity of the $\beta$-glucosidase enzyme. The concentrations of isoflavone aglycones using mixed cultures with a ratio of 
$1: 1: 1,2: 1: 1$, and $1: 1: 2$ were $0.271 \mathrm{mg} / \mathrm{mL}, 0.212 \mathrm{mg} / \mathrm{mL}$, and $0.273 \mathrm{mg} / \mathrm{mL}$ respectively.

\subsection{Optimization of Tofu Fermentation Using $10 \%$ Inoculum}

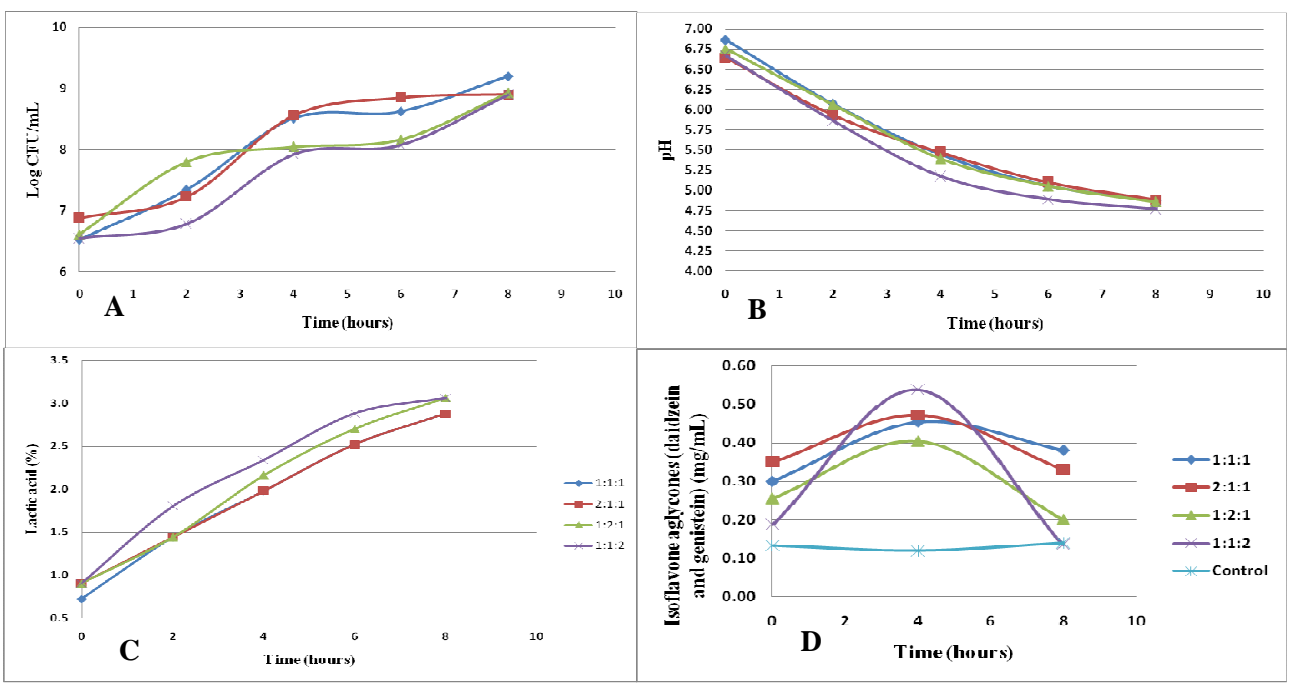

Figure 3 Optimization using 10\% inoculum; with the total amount of bacteria (A), $\mathrm{pH}(\mathrm{B})$, lactic acid (C), and isoflavone aglycones (daidzein + genistein) (D) changes during 8 hours of fermentation. The inoculum proportions between $L$. plantarum, L. acidophilus, and L. mesenteroides were 1:1:1, 2:1:1, 1:2:1, and $1: 1: 2$.

During the optimization process using 10\% inoculum (Figure 3A), all variations indicated an increase in the number of bacteria during fermentation. Almost all of the ratios showed the bacterial amount increase until the $4^{\text {th }}$ hour, then it remained stable until the $6^{\text {th }}$ hour, after which it rose again. The highest bacterial population growth rate with optimization using $10 \%$ inoculum (Figure $3 \mathrm{~A}$ ) was $0.078 \mathrm{~h}^{-1}$. This result was obtained with ratio $2: 1: 1$ (L. plantarum : L. acidophilus : L. mesenteroides), while the values of the highest specific growth rate of L. plantarum, L. acidophilus, and L. mesenteroides with the use of a single culture were $0.060 \mathrm{~h}^{-1}, 0.054 \mathrm{~h}^{-1}$, and $0.092 \mathrm{~h}^{-1}$ respectively. The lower bacterial growth rate using a mixed culture may have been caused by an antagonistic interaction between the lactic acid bacteria. This may have been caused by the production of an anti-bacterial peptide by L. mesenteroides [15].

All variations of ratios using $10 \%$ inoculum showed a decrease in $\mathrm{pH}$ and an increase of the lactic acid concentration during the fermentation process. The lowest $\mathrm{pH}$ value after fermentation (Figure $3 \mathrm{~B}$ ) was retrieved from ratio 1:1:2 
(L. plantarum : L. acidophilus : L. mesenteroides) with a $\mathrm{pH}$ value of 4.77 . The highest $\mathrm{pH}$ value was indicated by ratio $2: 1: 1$ with a $\mathrm{pH}$ value of 4.88 . This result is in accordance with the rate of production of lactic acid during the fermentation process (Figure 3C). The mixed-cultures ratio 1:1:2 (L. plantarum : L. acidophilus : L. mesenteroides) showed the highest lactic acid production rate with a value of $0.045 \% \mathrm{~h}^{-1}$, while ratio 2:1:1 showed the lowest lactic acid production rate with a value of $0.027 \% \mathrm{~h}^{-1}$.

The highest concentration of isoflavone aglycones (daidzein and genistein) with the use of $10 \%$ inoculum (Figure 3D) was indicated by ratio 1:1:1 (L. plantarum : L. acidophilus $: L$. mesenteroides) with a value of $0.381 \mathrm{mg} / \mathrm{mL}$. This first showed an increase in isoflavone aglycones, after which it decreased significantly from the $4^{\text {th }}$ to the $8^{\text {th }}$ hour. The increase in the isoflavone aglycones concentration may have been caused by the formation of daidzein and genistein by the $\beta$-glucosidase enzyme produced by the lactic acid bacteria [8], while the decrease in the isoflavone aglycones concentration may have been caused by a cell mechanism converting genistein to other compounds so it doesn't disturb cell division [14]. The isoflavone aglycones concentrations with ratios 2:1:1, 1:2:1 and 1:2:1 (L. plantarum : L. acidophilus : L. mesenteroides) were $0.331 \mathrm{mg} / \mathrm{mL}, 0.201 \mathrm{mg} / \mathrm{mL}$, and $0.135 \mathrm{mg} / \mathrm{mL}$ respectively.

\subsection{Optimization of Tofu Fermentation Using 12.5\% Inoculum}

The use of $12.5 \%$ inoculum (Figure 4A) showed that ratios 1:1:1 and 1:1:2 ( $L$. plantarum : L. acidophilus : L. mesenteroides) had a log phase, which means that the bacteria needed to adapt in the medium first. Ratios 1:1:1 (during the $4^{\text {th }}$ hour) and 1:2:1 (during the $6^{\text {th }}$ hour) showed a decrease in the bacterial amount. This may have been caused by the decline of the carbon source in the medium, in which case the bacteria needed to activate the enzyme to break down more complex carbon sources. The increased amount of bacteria after that may have been caused by activation of a bacterial enzyme that can be used to break down complex carbon sources in the medium.

The highest bacterial population growth rate using the $12.5 \%$ inoculum (Figure 4A) was $0.048 \mathrm{~h}^{-1}$. This result was obtained using ratio 1:1:2 (L. plantarum : $L$. acidophilus : L. mesenteroides). The highest values of the specific growth rates of $L$. plantarum, L. acidophilus, and L. mesenteroides using single cultures were $0.060 \mathrm{~h}^{-1}, 0.054 \mathrm{~h}^{-1}$ and $0.092 \mathrm{~h}^{-1}$ respectively. The growth rate values using mixed cultures were lower compared to when using single cultures. Most likely, the use of $12.5 \%$ inoculum led to an antagonistic interaction between the lactic acid bacteria. 
All of the ratios when using the addition of $12.5 \%$ inoculum showed a decrease of $\mathrm{pH}$ (Figure 4B) and an increase of lactic acid concentration during fermentation (Figure 4C). The changes in $\mathrm{pH}$ for each ratio did not show a significant difference during the fermentation process. The lowest $\mathrm{pH}$ value, indicated by ratio 1:2:1 (L. plantarum : L. acidophilus : L. mesenteroides), was 4.78, while the highest rate of lactic acid production was shown by ratio 1:1:2 with a value of $0.054 \% \mathrm{~h}^{-1}$. The highest rate of lactic acid production with the use of a single culture was obtained using $L$. mesenteroides, in which case the lactic acid production rate reached $0.126 \% \mathrm{~h}^{-1}$, while the rate of lactic acid formation by a single culture of $L$. plantarum and L. acidophilus were $0.072 \% \mathrm{~h}^{-}$ ${ }^{1}$ and $0.063 \% \mathrm{~h}^{-1}$. The addition of more L. mesenteroides (ratio 1:1:2) most likely caused the higher lactic acid production rates for that ratio.

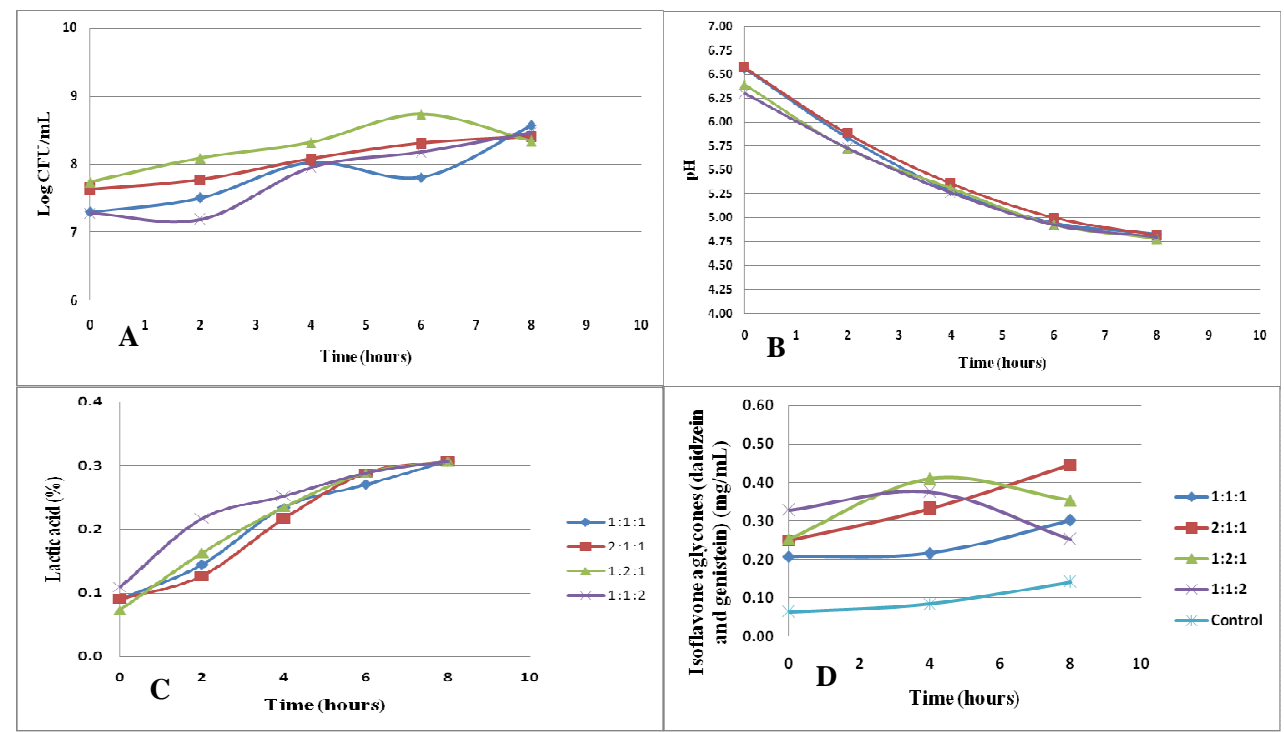

Figure 4 Optimization using $12.5 \%$ inoculum; with the total amount of bacteria (A), $\mathrm{pH}(\mathrm{B})$, lactic acid (C), and isoflavone aglycones (daidzein + genistein) (D) changes during 8 hours of fermentation. The inoculum proportions between $L$. plantarum, L. acidophilus, and L. mesenteroides were 1:1:1, 2:1:1, 1:2:1, and $1: 1: 2$.

Ratio 2:1:1 (L. plantarum : L. acidophilus : L. mesenteroides) showed the highest isoflavone aglycones (daidzein and genistein) concentration after eight hours of fermentation (Figure 4D). This ratio showed an increase of isoflavone aglycones during fermentation. This increase may have been caused by formation of daidzein and genistein by the $\beta$-glucosidase enzyme produced by the lactic acid bacteria [8]. The amount of isoflavone aglycones using ratio 2:1:1 was even higher compared to the other ratios at any percentage variation. 
The highest concentration of isoflavone aglycones using ratio 2:1:1 was 0.445 $\mathrm{mg} / \mathrm{mL}$. A previous study [13] has shown that tofu made using Lactobacillus plantarum produced $0.04124 \mathrm{mg} / \mathrm{mL}$ isoflavones aglycones. This shows that the use of a mixed culture of lactic acid bacteria may enhance the isoflavone aglycones concentration in tofu.

\section{Conclusion}

After measurement of the isoflavone aglycones concentration it can be inferred that the variation which gave the highest isoflavone aglycones content in tofu was $12.5 \%(2: 1: 1)$ (L. plantarum : L. acidophilus : L. mesenteroides). The highest bacterial population growth rate, the highest lactic acid production rate, and concentration of isoflavones aglycones (daidzein and genistein) obtained with this variation were $0.019 \mathrm{~h}^{-1}, 0.045 \% \mathrm{~h}^{-1}$, and $0.445 \mathrm{mg} / \mathrm{mL}$ respectively. For further study, we recommend to use the fermentation time as an additional parameter to produce tofu with a high isoflavones content and it may be better to include measurement of the activity of the $\beta$-glucosidase enzyme, which is known to have a role in isoflavone aglycones conversion. We also recommend the use of metabolomic analysis in further research to gain more insight into isoflavone aglycone production in tofu.

\section{References}

[1] USDA National Nutrient Database for Standard Reference, http://ndb.nal.usda.gov/ndb/foods/show/4817 (22 June 2013).

[2] Marathe, M.Y. \& Ghosh, J.S., Study of Proteinase Activity of Lactobacillus Plantarum, Intern. Journal of Genetics and Molecular Bio, 1(1), pp. 1-5, 2009.

[3] Florou-Paneri, P., Christaki, E. \& Bonos, E. Lactic Acid Bacteria as Source of Functional Ingredients, http://www.intechopen.com /books/lactic-acid-bacteria-r-d-for-food-health-and-livestock-purposes/ lactic-acid-bacteria-as-source-of-functional-ingredients (1 June 2013).

[4] Klein, K.O., Baron, J., Barnes, K.M., Pescovitz, O.H. \& Cutler Jr., G.B., Use of An Ultrasensitive Recombinant Cell Bioassay to Determine Estrogen Levels in Girls with Precocious Puberty Treated with An LHRH Agonist, J. Clin. Endocrinol. Metab., 83(7), pp. 2387-9, 1998.

[5] Xiao, C.W., Health Effects of Soy Protein and Isoflavones in Humans, J. Nutr., 138(6), pp. 12445-12495, 2008.

[6] Barnes, S., Evolution of the Health Benefits of Soy Isoflavones, Exp. Biol. Med., 217(3), pp. 386-396, 1998.

[7] Hendrich, S., Bioavailability of Isoflavones, J. Chromatogr. B. Analyt. Technol. Biomed. Life Sci., 777(1-2), pp. 203-10, 2002. 
[8] Galvez, A., Abriouel, H., Lopez, R.L. \& Omar, N.B., Bacteriosin-based Strategies for Food Biopreservation, Intern. J. of Food Microbiol., 120(12), pp. 51-70, 2007.

[9] Marasco, R., Muscariello, L., Varacamonti, M., De Felice, M. \& Sacco, M., Expression of the bglH Gene of Lactobacillus Plantarum is Controlled by Carbon Catabolite Repression, J. Bacteriol., 180(13), pp. 3400-4, 1998.

[10] Otieno, D.O., Stability of Bioactivae Isoflavones anf Glycolytic Enzymes Produced By Probiotic Bacteria in Soy based Food During Processing and Storage, Thesis, School of Molecular Sciences, Victoria University, Werribee, Australia, 2007.

[11] Gueguen, Y., Chemardin, P., Labrot, P., Arnaud, P. \& Galzy, P., Purification and Characterization of an Intracellular $\beta$-glucosidase from a New Strain of Leuconostoc Mesenteroides Isolated from Cassava, J. Appl. Microbiol., 82(4), pp. 469-476, 1997.

[12] Cappuccino, J.G. \& Sherman, N., Microbiology a Laboratory Manual, $8^{\text {th }}$ ed., Pearson/Benjamin Cummings, San Fransisco, CA, 2008.

[13] Saksono, B., Triatna, L., Wulandari P.S. \& Octavia, Y., Produksi Tahu Berisoflavon Tinggi., Laporan Teknik Kegiatan Penelitian Pusat Penelitian Bioteknologi, 2007.

[14] Liew, R., Williams, J.K., Collins, P. \& Macleod, K.T., Soy-Derived Isoflavones Exert Opposing Actions on Guinea Pig Ventricular Myocytes, J. Pharmacol. Exp. Ther., 304(3), pp. 985-93, 2003.

[15] Todorov, S.D. \& Dicks, L.M., Characterization of Mesentericin ST99, a Bacteriocin Produced by Leuconostoc Mesenteroides Subsp. Dextranicum ST99 Isolated from Boza, J. Ind. Microbiol. Biotechnol., 31(7), pp. 323-9, 2004. 